\title{
A limping dinosaur in the Late Jurassic: Pathologies in the pes of the neornithischian Othnielosaurus consors from the Morrison Formation (Upper Jurassic, USA)
}

\section{Penélope Cruzado-Caballero, Ignacio Díaz-Martínez, Bruce Rothschild, Malcolm Bedell \& Xabier Pereda-Suberbiola}

To cite this article: Penélope Cruzado-Caballero, Ignacio Díaz-Martínez, Bruce Rothschild, Malcolm Bedell \& Xabier Pereda-Suberbiola (2020): A limping dinosaur in the Late Jurassic: Pathologies in the pes of the neornithischian Othnielosaurus consors from the Morrison Formation (Upper Jurassic, USA), Historical Biology, DOI: 10.1080/08912963.2020.1734589

To link to this article: https://doi.org/10.1080/08912963.2020.1734589

曲 Published online: 02 Mar 2020.

Submit your article to this journal $₫$

Q View related articles \ulcorner

View Crossmark data \lceil 


\title{
A limping dinosaur in the Late Jurassic: Pathologies in the pes of the neornithischian Othnielosaurus consors from the Morrison Formation (Upper Jurassic, USA)
}

\author{
Penélope Cruzado-Caballero $\mathbb{D}^{\mathrm{a}, \mathrm{b}}$, Ignacio Díaz-Martínez ${ }^{\mathrm{a}}$, Bruce Rothschild ${ }^{c}$, Malcolm Bedell ${ }^{\mathrm{d}}$ and Xabier Pereda- \\ Suberbiola ${ }^{\mathrm{e}}$
}

aCONICET, Instituto de Investigación en Paleobiología y Geología, Universidad Nacional de Río Negro, General Roca, RN, Argentina; bGrupo AragosaurusIUCA, Departamento de Ciencias de la Tierra, Área de Paleontología, Universidad de Zaragoza, Zaragoza, Spain; 'Carnegie Museum, Pittsburgh, PA, USA; 'Western Interior Paleontological Society, Denver, CO, USA; 'Departamento de Estratigrafía y Paleontología, Facultad de Ciencia y Tecnología, Universidad Del País Vasco/Euskal Herriko Unibertsitatea (UPV/EHU), Bilbao, Spain

\begin{abstract}
The study of palaeopathology provides valuable information about injury and behaviour in extinct organisms. Appendicular pathologies are interesting as they directly affect mobility and therefore the ability of an animal to survive. Here, the injuries recorded in the left pes of the neornithischian Othnielosaurus consors are described. The implications of these injuries in its behaviour are also discussed. Othnielosaurus shows pathological features in all its pes digits, with three types of pathologies have been identified: calcium pyrophosphate deposition disease (CPPD), and pilon and impact fractures. Calcium pyrophosphate deposition disease is visible on the articular surface of phalange II-3 as a small osseous plaque. A pilon fracture is evidenced by the growth of callus tissue on the shaft of the phalange I- 1 and demonstrates healing before death. The impact fractures are identified as a focal subsidence on the articular surfaces of phalanges III-1 and IV-4, which are partially healed. Perhaps the suite of palaeopathologies encountered would generate pain and discomfort when walking, which probably resulted in a limp that would have impacted on its lifestyle. Finally, the fact that the fractures are in different stages of healing would suggest that impact fractures could have contributed to the death of the individual.
\end{abstract}

\section{ARTICLE HISTORY}

Received 21 October 2019

Accepted 20 February 2020

\section{KEYWORDS}

Impact fracture; pilon fracture; CPPD; Jurassic; ornithischia

\section{Introduction}

Palaeopathology studies the presence of injuries and their appearance in the fossil record (Rothschild and Martin 2006). This provides valuable information about the behaviour, environmental interactions and lifestyles of ancient organisms (see Rothschild et al. 2012; Kappelman et al. 2016 for tetrapod examples). It is relatively common to find traumas or other pathologies in Mesozoic dinosaur bones (see Arbour and Currie 2011; Peterson and Vittore 2012 and references therein). For instance, the presence of impact fractures in theropods (Rothschild 2009) can reveal that hunting is also dangerous for the hunter, or the particular facial lesions in specimens of Triceratops may demonstrate the effects of periodic intraspecific combats (Farke et al. 2009). In bipedal dinosaurs, the fracture record is not as abundant in theropods (Rothschild and Martin 2006; Anné et al. 2015) as in ornithopods (diverse clade of bipedal herbivorous ornithischians that includes 'hypsilophodontids' and iguanodontians, such as dryosaurids, camptosaurids basal iguanodontoids and hadrosaurids; Gilmore 1912; Blows 1989; Norman et al. 2004; Butler et al. 2008; Witzmann et al. 2008; Straight et al. 2009; Butler and Barrett 2012; Tanke and Rothschild 2014; Ramírez-Velasco et al. 2017; Herne et al. 2018), pachycephalosaurids (Peterson and Vittore 2012) or ceratopsians (Rothschild and Martin 2006; Hedrick et al. 2016). Furthermore, the presence of fractures in associated pedal elements is even scarcer, and they are principally reported in the clade Hadrosauridae (Rothschild and Tanke 2006; Tanke and Rothschild 2014).
Fractures, such as a broken bone, cartilage or both (Waldron 2008), are a useful type of pathology from which to infer behaviour (Rothschild and Martin 2006; Arbour and Currie 2011; Rothschild et al. 2012; Kappelman et al. 2016). According to Rothschild and Martin (2006) the factors affecting the occurrence of a fracture relate to the nature of the force (magnitude, direction, loading rate, and duration) and the osseous area of distribution of that force (density, fatigue strength, resilience, and elasticity). Depending on the relationship between these factors, there are several types of fracture: oblique (which can be closed or displaced), transverse, greenstick, spiral, compression, impact, and stress (Rothschild and Martin 2006).

The presence of fractures in dinosaur tends to be more abundant in the axial skeleton and proximal areas of the body (Rothschild and Martin 2006; Arbour and Currie 2011; Peterson and Vittore 2012; Hearn and Williams 2019). Although it is common to find pedal elements in the tetrapod fossil record, they are not usually preserved together after death, so it is difficult to find a complete pes. Autopodia tends to separate into their individual components during the early postmortem stage and are easily transported by water currents. (Voorhies 1969; Conybeare and Haynes 1983; Hill and Behrensmeyer 1984).

While primary osteoarthritis is extremely rare in dinosaurs (Rothschild 1990), a form of crystalline arthritis, calcium pyrophosphate deposition disease (CPPD, a rheumatic disease which is thought to be secondary to abnormal accumulation of calcium pyrophosphate dihydrate crystals within joint soft tissues) has been identified. CPPD typically is recognised by chondrocalcinosis or pseudogout (Rothschild 2005, 2007; Jacobson et al. 2008; 
Rothschild and Bruno 2009; Rothschild et al. 2013). The former is recognised as calcification on joint surfaces, while the latter is the term used when inflammation is present. The presence of calcified sheet deposition on articular surfaces is definitive for the diagnosis (Rothschild and Martin 2006). This disease is common in mammals (Rothschild 2005; de Souza Barbosa et al. 2014), dinosaurs (Anné et al. 2015), including birds (Angel 2007) and other reptiles (Rothschild and Martin 2006; Rothschild 2010; Rothschild et al. 2013).

Here we present the pathological record of the almost complete left pes of the neornithischian Othnielosaurus consors (YPM VP 1882; Figure 1) from the Upper Jurassic Morrison Formation of Wyoming (USA). The main goals of the present paper are: (1) to describe the injuries registered in the left pes YPM VP 1882; and (2) to hypothesise on the possible implications of these injuries in the behaviour of Othnielosaurus consors.

\section{Specimen studied and taxonomic assignment}

YPM VP 1882 includes at least two partial skeletons discovered by O. C. Marsh in 1879 (Marsh 1894) at W. H. Reed's YPM Quarry 7 'Three Trees Quarry' in Como Bluff, Albany County, Wyoming, USA (Ostrom and McIntosh 1966:53; map in fig. 3). The stratigraphic position of the type locality is given by Bakker et al. (1990, fig. 1 left).

The material was found in a green-grey mudstone of the Brushy Member or upper member of the Morrison Formation (Galton 1983).

In YPM VP 1882, the neural arches and centra of the vertebrae are fused (Carpenter and Galton 2018), so it might be considered that the material belongs to osteologically subadult or adult individuals. Based on skeletal measurements, Othnielosaurus was a small dinosaur, about $1.5 \mathrm{~m}$ in length.

Following Galton, 'the proximal phalanges of digits II and IV should be transposed and when this is done the fourth digit is no longer unusually elongate' (see Galton 1983, p. 224, fig. 6Z). Recently, Carpenter and Galton (2018) illustrated the left pes of YPM VP 1882 (erroneously labelled by them as 1822) in anterior and posterior views. Here, we have reordered the pedal elements according to the recommendations of Dieudonné et al. (2016), and identify new assignments: i.e., Phalanx II-2 of Carpenter and Galton (2018, fig., p. 18) is considered here as III-3 due to its symmetry and its arrangement with the phalanx III-2. Phalanx II-1 of Carpenter and Galton (2018) is regarded here as belonging to digit IV, as IV-1, taking into account the lateral asymmetry and the ventral development of its proximal area. On the other hand, phalanges III- 3 and IV-1 by Carpenter and Galton (2018) were not found in the collections when the visit was made, but a new unpublished phalanx is identified there that would correspond by its medial asymmetry and proximal shape with phalanx II-1 (see Figure 1).

YPM VP 1882 was originally referred to Laosaurus consors by Marsh (1894, 1896). This assignment was followed by subsequent authors (e.g., Gilmore 1925; Ostrom and McIntosh 1966; Galton and Jensen 1973). Galton (1977), Galton (1981), 1983) proposed that $L$. consors is referable to Othniela rex, but subsequently reassigned YPM VP 1882 to the new genus Othnielosaurus as O. consors (Galton 2007). In a recent paper, Carpenter and Galton (2018) considered Nanosaurus agilis as a senior synonym of Othnielosaurus consors and Othnielia rex (also Drinker nisti, named by Bakker et al. 1990), all taxa based on fossil remains from the Upper Jurassic Morrison Formation of western USA. Until consensus is reached, we prefer to assign provisionally YPM VP 1882 to Othnielosaurus consors.

Othnielosaurus (formerly under the names Laosaurus, Nanosaurus or Othnielia) has classically been considered to be an ornithopod (e.g., Marsh 1894, 1896; Gilmore 1925), and commonly classified among the hypsilophodontids (i.e., Galton 1977, 1983; Sues and Norman 1990). Currently, Hypsilophodontidae appears to represent a paraphyletic grade of basal neornithischian and basal ornithopod taxa (Norman et al. 2004; Butler et al. 2008). Norman et al. (2004) regarded Othnielia as a basal euornithopod less derived than Hypsilophodon (see Galton 2007). However, recent phylogenetic analyses place Othnielosaurus outside of Ornithopoda as a non-cerapodan, basal neornithischian (e.g., Butler et al. 2008; Han et al. 2012; Boyd 2015).

In summary, the taxonomic status of Othnielosaurus consors is currently under debate. It could be a valid taxon or a junior synonym of Nanosaurus agilis. Its phylogenetic position is problematical as well: Long considered as an ornithopod, the most recent analyses support that it represents a basal neornithischian.

\section{Institutional abbreviations}

YPM VP, Yale Peabody Museum of Natural History, Division of Vertebrate Palaeontology, Yale University, New Haven, Conne cticut, USA.

\section{Description and pathological diagnoses}

YPM VP 1882 includes an almost complete left pes of Othnielosaurus consors (Figure 1). Nearly all the metatarsals and phalanges are preserved, except for the proximal part of metatarsal I and the phalanges I-2 and II-2. The morphology of both the metatarsals and the phalanges is similar to that of other basal ornithischians or basal ornithopods (Norman 2004; Norman et al. 2004). The pes shows pathological features in all digits (Figure 1), as described below.

\section{Pedal phalanx I-1}

Phalanx I-1 exhibits considerable growth of pathological bone covering some two-thirds of the element and an oblique displacement of the distal half of the phalanx which is angulated dorsomedially. These two factors indicate an old transverse fracture through the diaphysis (Figures 1(a1-a3) and 2(a)). This growth increases the mediolateral width of the diaphysis relative to unmodified elements (phalanx II-1 to IV-1). The callous tissues do not reach the proximal and distal ends where both articular surfaces maintain their original shape and texture. The surface of the callous has a slightly irregular texture, as is common in a fractured bone, and its maximum growth is around the middle of the phalanx. The abnormal growth increases the width of the phalanx to $18.4 \mathrm{~mm}$ at the central shaft (phalanx II-1, the most similar, has a normal width of $12.5 \mathrm{~mm}$ ). Coinciding with the callous tissues on dorsal and plantar views is a fracture line perpendicular to the axis, located at a mid of the phalangeal shaft (Figure 1(a1-a2)). In dorsal view, it can be observed that the shaft has been pushed up relative to the dorsal and medial sides by compression forces. In plantar view, the absence of correct alignment of the phalanx before healing can be observed, resulting in minor displacement of the axis. Last, there is a pathological rectangular subsidence (marked by a scratched area in Figure 1(a1-a2)). in the dorsoproximal area of the shaft.

The presence of reactionary bone growths allows refutation of the possibility that the damage resulted from a post-mortem or taphonomic modification.

\section{Pathological diagnosis}

The presence of an external fracture line and callous tissues indicates healing. Minor displacement of the axis as result of the relative upward thrust of the shaft, implies slight shortening of the diaphysis. Both are characteristic of a pilon fracture (a fracture in which the proximal portion of a fractured bone actually penetrates into the 
a.1.
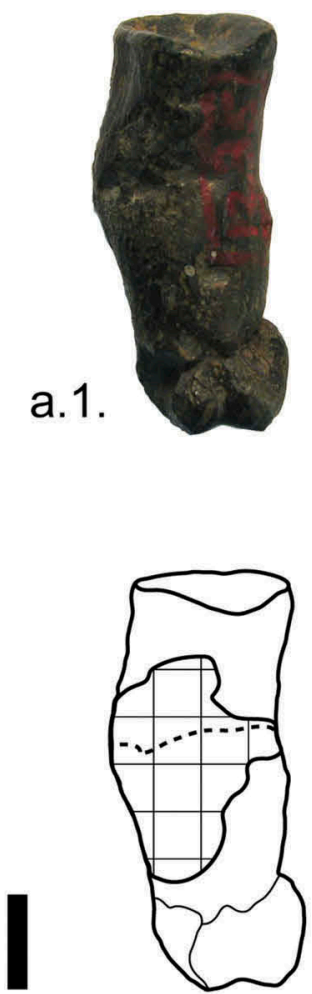

a.2.

b
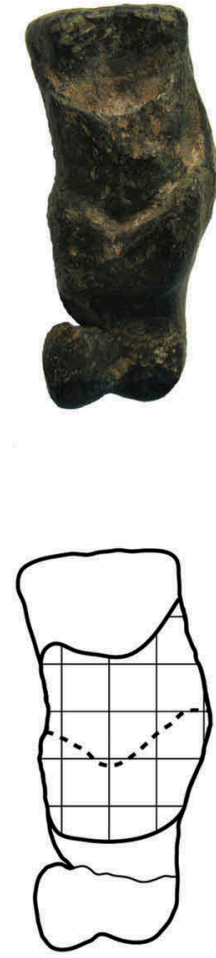
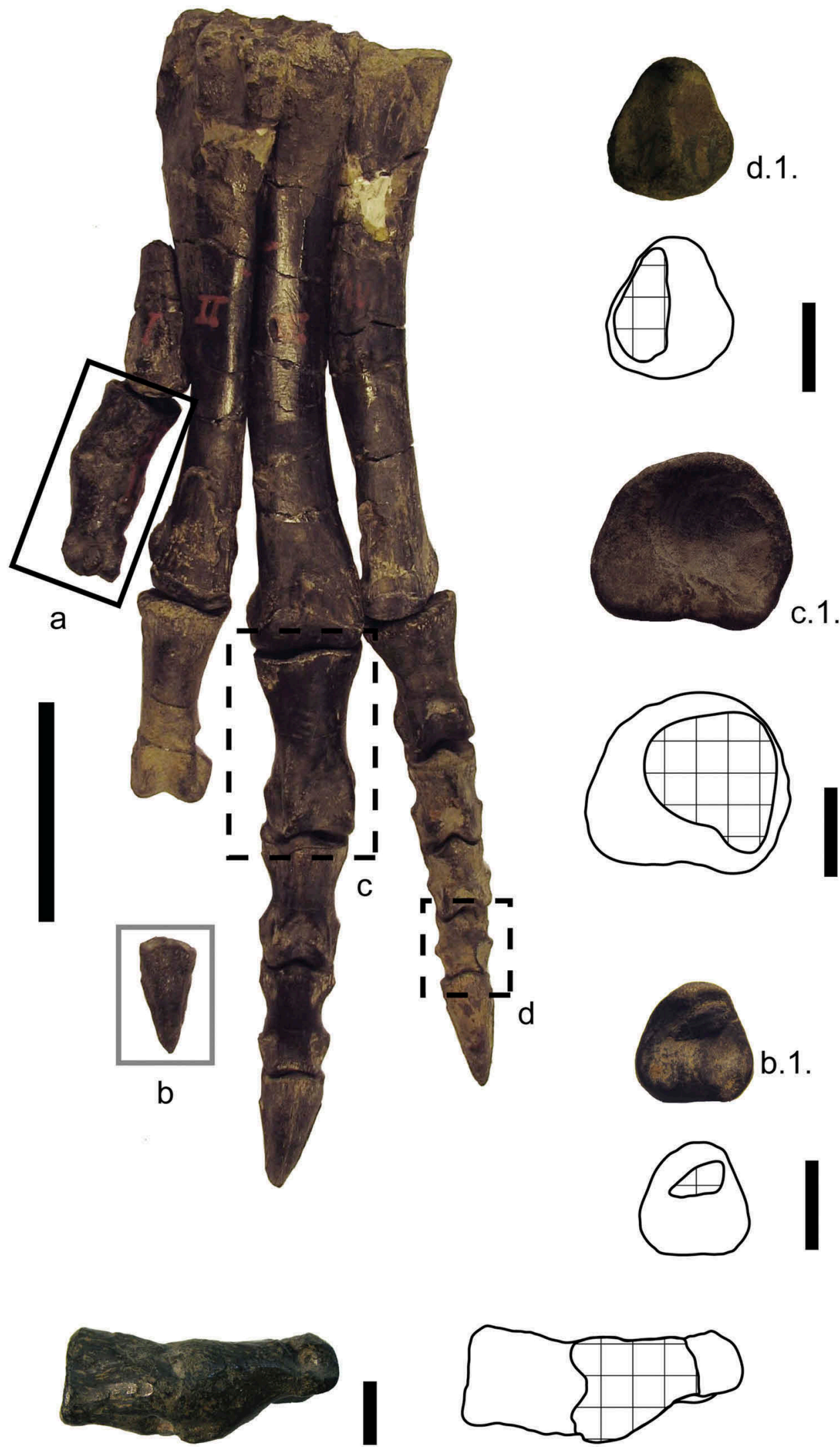

\section{a.3.}

Figure 1. Left pathological pes of Othnielosaurus (YPM VP 1882) in dorsal view. (a) Pedal phalanx I-1, (a.1-3) in dorsal, plantar and lateral views, respectively; (b) pedal phalanx II-3, (b.1) in proximal view; (c) pedal phalanx III-1, (c.1) in proximal view; (d) pedal phalanx IV-4, (d.1) in proximal view. Black rectangle, pilon fracture; rectangle with a dashed line, calcium pyrophosphate deposition disease (CPPD); grey rectangle, impact fracture. Area scratched in the drawing, pathological zone, and the dashed line in the draw A1 indicate the fracture line. Scale bar of the pes $=5 \mathrm{~cm}$. a-d and a.1-d.1 scale bar $=1 \mathrm{~cm}$. 
distal portion). This is caused by a high-energy impact and as a consequence the force acts along the long axis of the bone and crushing and shortening of the bone occurs (Bourne et al. 1983; Helfet et al. 1994; Haller et al. 2017).

\section{Pedal phalanx II-3}

Pedal phalanx II-3 has a small teardrop-shaped calcified plaque (approximately $0.5 \mathrm{~cm}$ ) situated on the dorsomedial quadrant of the proximal articular surface. It has a sclerotic margin parallel to the articular surface associated with crumbling edges (Figures 1(b) and 2(c)). This sheet is absent in the other conserved ungual phalanges (Figure $2(\mathrm{c}-\mathrm{j})$ ).

The presence of a calcified sheet, sharply defined, and retention of bone integrity allow refutation of the possibility that the deposit resulted from taphonomic modification.

\section{Pathological diagnosis}

The presence of a calcific sheet on the joint surface of the phalanx is compatible with calcium pyrophosphate deposition disease (CPPD). This disease is a variety of a crystalline and erosive arthritis that can be recognise by the presence of calcified sheet deposited, of small size, sharply defined, with characteristic sclerotic margins and retention of underlying bone integrity. When the CPPD affects to the hands and feet, it is characterised by being predominantly marginal in its distribution, affecting 1-2 joints, and tending to have a subchondral distribution in the absence of new bone formation. The affected joints reflect that of the non-erosive component of CPPD (Rothschild and Martin 2006)

\section{Pedal phalanges III-1 and IV-4}

Structural weakening produced collapse (focal subsidence) of the bone of the proximal articular surfaces (Figures $1(\mathrm{c}-\mathrm{d})$ and $2(\mathrm{f}-\mathrm{j})$ ). In digit III the area collapse is circular and covers almost all the articular surface. In digit IV, it has a drop-shape and only covers the left half of the surface. Such collapse is absent in the other preserved phalanges (Figure $2(\mathrm{~d}-\mathrm{j})$ ).

The presence in the area of collapse, of a smooth articular surface without parallel cracks and polygonal fracture patterns (which commonly characterise subaerially exposed and eroded bone surfaces) (Peterson and Vittore 2012), indicates that such damage was not the result of a post-mortem or taphonomic modification.

\section{Pathological diagnosis}

Focal subsidence is the loss of bone as a result of inflammation and decreased blood flow. The loss of blood supply is a complication that usually occurs after a fracture, resulting in avascular necrosis and bone collapse and/or reabsorption (Waldron 2008). The absence of new bone on the articular surface and fibrous and disorganised surface texture indicates that it is a partially healed fracture. This appearance contrasts with the foreshortening and splaying that typically result from the plafond or pilon fractures (Bourne et al. 1983; Helfet et al. 1994; Haller et al. 2017). It also differs from the 'divot fracture', wherein force applied to a small section of diaphyseal or metaphyseal bone produces an incomplete fracture with displacement of fragments into the medullar cavity (Rose et al. 1988; Resnick 2002). The presence of focal subsidence is characteristic of an impact fracture, in which a portion of articular subchondral bone has broken free of the metaphysis (Wolfe and Katz 1995; Sullivan et al. 2000; Rothschild et al. 2012).

Differential considerations for impact fractures include osteochondrosis and infectious arthritis. Osteochondrosis defines failure of articular cartilage to transform into the subchondral bone during normal development (Resnick 2002). It has the form of focal, sharply defined, deep articular surface depressions, as previously reported in theropod and hadrosaurid phalanges (Bell and Coria 2013; Tanke and Rothschild 2014). In contrast, infectious arthritis typically presents with reactive growth of new bone around the periphery of the lesion, filigree reaction on the bone surface, draining sinuses, and distortion of the underlying bone (Rothschild and Martin 2006). The absence of these signs in YPM VP 1882 suggests that the impact fractures are probably not a result of infectious arthritis.

\section{Implications on behaviour}

The record of pathological fractures in dinosaurs is sparse. When present they are predominantly distributed in the axial and appendicular areas (Rothschild and Martin 2006; Arbour and Currie 2011; Peterson and Vittore 2012 and references therein). These authors documented several types of fractures present in dinosaur skeletons, including compound, impact, green-stick and stress fractures. Fractures have implications for behaviour, both in the predator and in the prey, as well as possible intraspecific interactions (Rothschild 2009; Arbour and Currie 2011; Rothschild et al. 2012; Kappelman et al. 2016).

Three different pathologies have been observed in the pes of YPM VP 1882: two types of fractures (pilon and impact) and CPPD, a pathology which may be metabolic, familial or idiopathic in origin (Rothschild and Martin 2006; Rothschild 2010). Pilon fractures were interpreted as caused by impact during a fall (Kappelman et al. 2016), and impact fractures, by relatively low impact contact with the substrate, either by the animal jumping, landing on uneven ground, or during running (Sullivan et al. 2000).

Calcium pyrophosphate deposition disease (CPPD) affects the articular surface of pedal phalanx II-3. Phalanx II-2 is not preserved, so it not possible to know whether the presence of calcification also affected (or not) its articular face. Although this arthropathy was not dangerous to the integrity of Othnielosaurus, it likely would increase the discomfort of walking caused by the defects in phalanges III- 1 and IV-4.

It is important to note that the fractures present different healing stages. While the pilon fracture is completely healed, the impact fractures are only partially healed. Therefore, we hypothesise that this individual suffered at least two traumatic events of different intensities before death. The first one, which generated the pilon fracture, is related to a high-energy impact such as a fall, possibly a consequence of inter- or intraspecific interactions. Complete healing of the fracture confirms the survival of the traumatic event but was insufficient for resorption of the callous tissues, the last stage of fracture healing (Anné 2014; Arbour and Currie 2011). The second event resulted in at least two unhealed impact fractures in the phalanges III-1 and IV-4, as the result of a low energy impact. Basal ornithischians and basal ornithopods are considered as tetradactyl or tridactyl digitigrade bipedal dinosaurs (Thulborn 1990). Nevertheless, Norman et al. (2004) pointed out that digit I was not long enough to touch the ground during locomotion. In this way, it is possible that the pilon fracture in the phalanx I-1 of YPM VP 1882 may not have significantly affected locomotion (as there was no significant contact of this digit with the ground). This 'protected status' would facilitate fracture healing. During the healing period the pathology likely caused discomfort and pain, due to the tendon action of M. flexor hallucius longus (Carrano and Hutchinson 2002). In this way, every time Othnielosaurus took a step, the tendon would have exerted pressure on the fracture that would likely have resulted in pain and protective behaviour related to use of the injured limb (Hearn and Williams 2019). On the other 
a

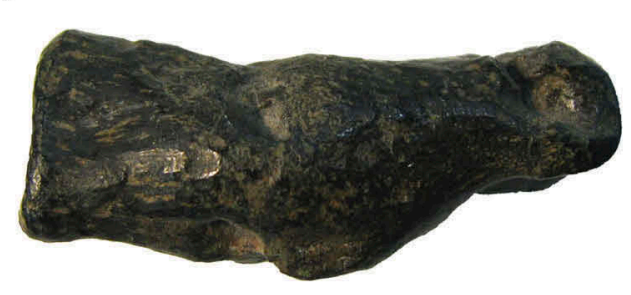

b

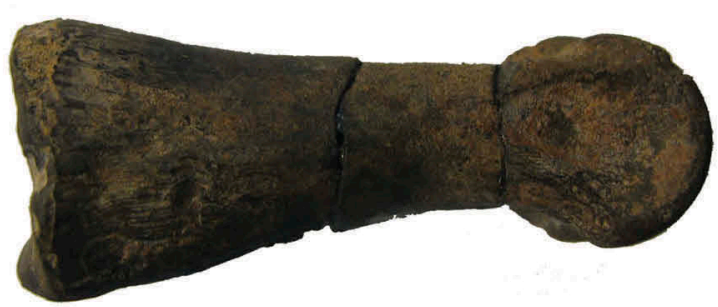

d

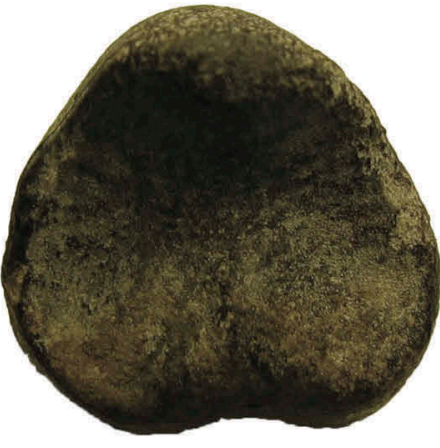

e

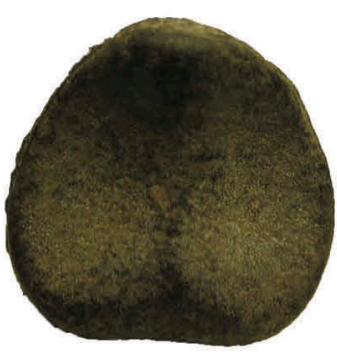

C

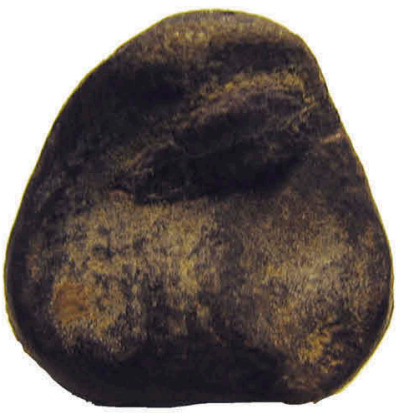

f
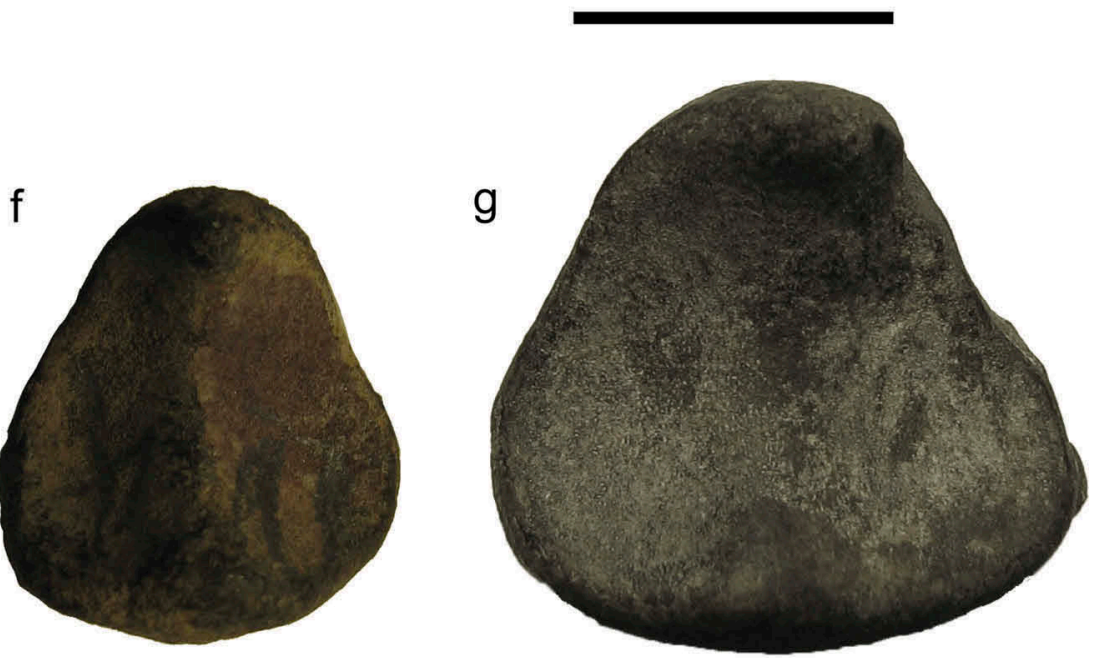
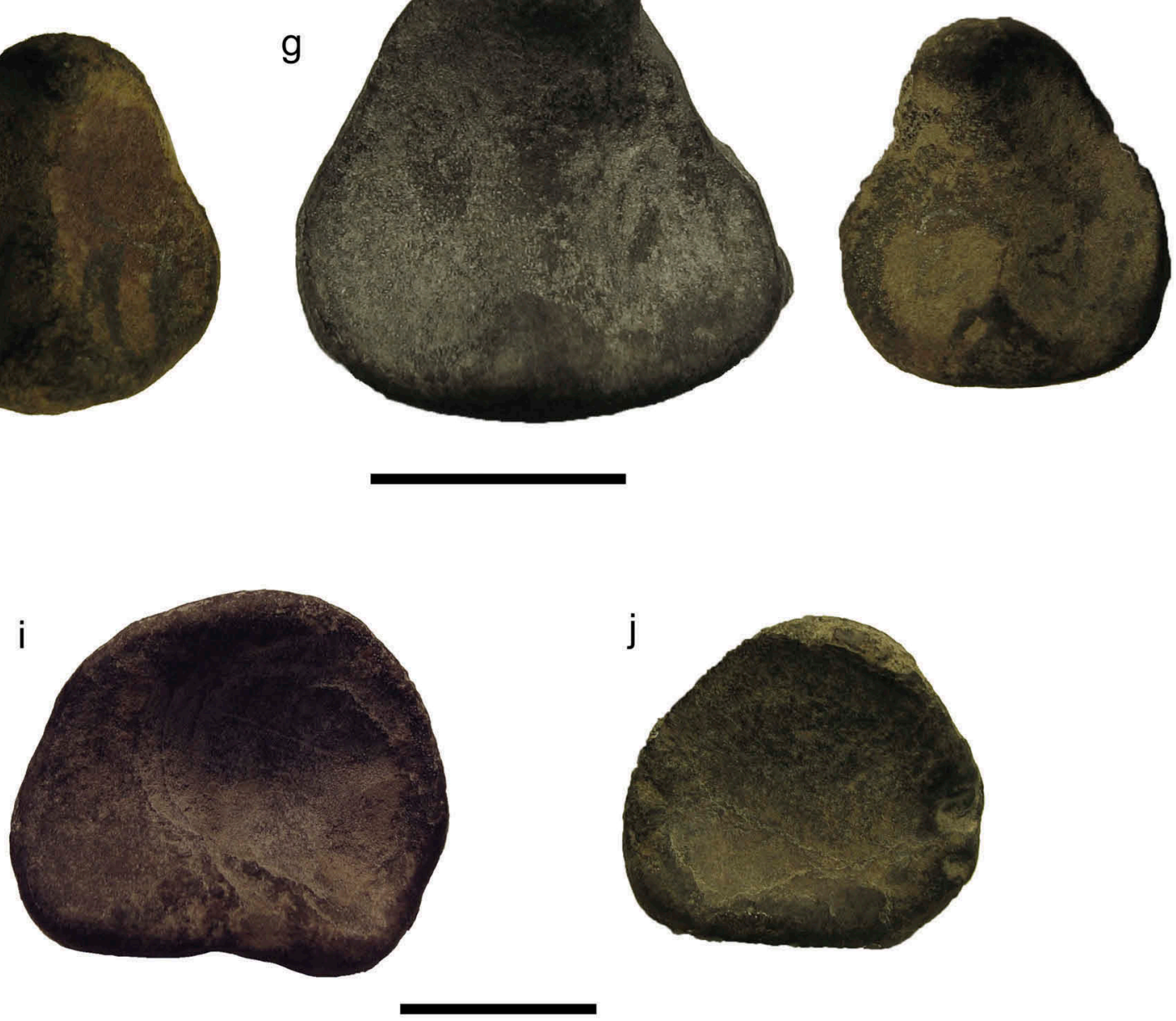

Figure 2. Pathological and healthy phalanges of Othnielosaurus (YPM VP 1882). (a) Pedal phalanx I-1, (b) pedal phalanx II-1, (c) pedal phalanx II-3, (d) pedal phalanx III-4, (e), pedal phalanx IV-5, (f) pedal phalanx IV-4, (g) pedal phalanx III-2, (h) pedal phalanx IV-2, (i) pedal phalanx III-1, (j) pedal phalanx II-1. (a, c, f and i), pathological phalanges, (b, $d-e, g-h$ and j) healthy phalanges. (a-b) in lateral view, $c-j$ in proximal views. Scale bar $=1 \mathrm{~cm}$. 
hand, the impact fractures located in the phalanges III-1 and IV-4, which supported the weight of Othnielosaurus on the ground, might had causing chronic pain and, consequently, a limp. Similar cases of pedal pathologies affecting an individual's mobility have been described in the fossil record of dinosaurs, crocodyliforms and mammals, including hominoids (Hanna 2002; Farke and O'Connor 2007; Cabral et al. 2011; Anné et al. 2014; Foth et al. 2015; McCrea et al. 2015; Macdonald and Currie 2018; Hunt et al. 2019). Survival of lesions of weight-bearing bone would have greater consequence for obligate bipeds and evidence of lesions healing in these bones is rare (Hearn and Williams 2019). Pilon fractures likely produced more marked lameness in Othnielosaurus than impact fracture. The presence of Othnielosaurus pedal pathologies may have contributed to reduced ability to obtain food with subsequent malnutrition, greater susceptibility to other diseases and complications, and higher risk of predation (Gross et al. 1993; Hanna 2002; Cabral et al. 2011; Foth et al. 2015; Hunt et al. 2019).

\section{Conclusions}

The results obtained in the analysis of pathologies in the left pes of Othnielosaurus indicate that the dinosaur suffered a form of arthritis, which can be metabolic, familial, or idiopathic in origin and at least two accidental events during its life. The injuries resulting from both accidents (pilon and impact fractures) were likely painful events and likely resulted in a reduction in activity. It is likely that this individual had difficulty walking and did so with a limp. That could have interfered with obtaining food, compromised ability to escape from predators, and increased susceptibility to illness. Finally, the state of incomplete healing of impact fractures indicates that this Othnielosaurus did not survive sufficiently long after the injuries for complete healing to occur. It is unclear if these pathologies contributed directly or indirectly (e.g., reducing predator avoidance efficacy) to its death.

\section{Acknowledgments}

We thank Daniel Brinkman curator of the Yale Peabody Museum provided access to the specimens in his care. We acknowledge an anonymous reviewer for the comments and suggestions that have helped improve the manuscript.

\section{Disclosure Statement}

No potential conflict of interest was reported by the authors.

\section{Funding}

Financial support has been provided by the Spanish Ministerio de Ciencia e Innovación and the European Regional Development Fund [CGL201785038-P]; partially by the Agencia Nacional de Promoción Científica y Técnica [PICT 0920-2015; PICT 2016-0491]; partially by the Universidad Nacional de Río Negro [PI 40-A-572; PI 40-A-660; PI 40-A-737]; by the Universidad del País Vasco/Euskal Herriko Unibertsitatea [UPV/EHU, research group PPG17/05] and by the Gobierno Vasco/EJ [research group IT1418-19].

\section{ORCID}

Penélope Cruzado-Caballero iD http://orcid.org/0000-0002-5819-8254

\section{References}

Angel R. 2007. Metabolic disorders: limitations to growth of and mineral deposition into the broiler skeleton after hatch and potential implications for leg problems. J Appl Poult Res. 16(1):138-149.

Anné J. 2014. Fossil focus: diagnosing dinosaurs. Palaeontology Online. 4 (8):1-7.
Anné J, Edwards NP, Wogelius RA, Tumarkin-Deratzian AR, Sellers WI, van Veelen A, Bergmann U, Sokaras D, Alonso-Mori R, Ignatyev K, et al. 2014. Synchrotron imaging reveals bone healing and remodelling strategies in extinct and extant vertebrates. J R Soc Interface. 11(96):20140277.

Anné J, Garwood RJ, Lowe T, Withers PJ, Manning PL. 2015. Interpreting pathologies in extant and extinct archosaurs using micro-CT. PeerJ. 3:e1130.

Arbour VM, Currie PJ. 2011. Tail and pelvis pathologies of ankylosaurian dinosaurs. Hist Biol. 23(4):375-390.

Bakker RT, Galton PM, Siegwarth J, Filla J. 1990. A new latest Jurassic vertebrate fauna, from the highest levels of the Morrison Formation at Como Bluff, Wyoming, with comments on Morrison biochronology. Hunteria. 2(6):1-19.

Bell PR, Coria RA. 2013. Palaeopathological survey of a population of Mapusaurus (Theropoda: carcharodontosauridae) from the Late Cretaceous Huincul Formation, Argentina. PloSOne. 8(5):e63409. doi:10.1371/journal. pone.0063409

Blows WT. 1989. A pelvic fracture in Iguanodon. Archosaurian Articulations. 1 (7):49-50.

Bourne RB, Rorabeck CH, Macnab J. 1983. Intra-articular fractures of the distal tibia: the pilon fracture. J Trauma. 23(7):91-596.

Boyd CA. 2015. The systematic relationships and biogeographic history of ornithischian dinosaurs. PeerJ. 3:e1523.

Butler RJ, Barrett PM. 2012. Ornithopods. In: Brett-Surman MK, Holtz TR Jr., Farlow JO, editors. The complete dinosaur. 2nd ed. Bloomington \& Indianapolis: Indiana University Press; p. 550-566.

Butler RJ, Upchurch P, Norman DB. 2008. The phylogeny of the ornithischian dinosaurs. J Syst Palaeontol. 6(1):1-40.

Cabral UG, Riff D, Kellner AW, Henriques DD. 2011. Pathological features and insect boring marks in a crocodyliform from the Bauru Basin, Cretaceous of Brazil. Zool J Linnean Soc. 163(suppl_1):S140-S151.

Carpenter K, Galton PM. 2018. A photo documentation of bipedal ornithischian dinosaurs from the upper Jurassic Morrison Formation, USA. Geol Intermountain West. 5:167-207.

Carrano MT, Hutchinson JR. 2002. Pelvic and hindlimb musculature of Tyrannosaurus rex (Dinosauria: theropoda). J.Morphol. 253(3):207-228.

Conybeare A, Haynes G. 1983. Observations on elephant mortality and bones in water holes. J Quaternary Res. 22(2):189-220.

de Souza Barbosa FH, de Oliveira Porpino K, Fragoso ABL, Oliveira EV. 2014. Arthritis in a glyptodont (Mammalia, Xenarthra, Cingulata). PloSOne. 9(2): e88646.

Dieudonné PE, Tortosa T, Torcida-Fernández Baldor F, Canudo JI, DíazMartínez I. 2016. An unexpected early rhabdodontid from Europe (Lower Cretaceous of Salas de los Infantes, Burgos Province, Spain) and a re-examination of basal iguanodontian relationships. PloSOne. 11(6):e0156251.

Farke AA, O'Connor PM. 2007. Pathology in Majungasaurus crenatissimus (Theropoda: abelisauridae) from the Late Cretaceous of Madagascar. J Vertebr Paleontol. 27(S2):180-184.

Farke AA, Wolff EDS, Tanke DH. 2009. Evidence of combat in Triceratops. PLoSOne. 4:e4252.

Foth C, Evers SW, Pabst B, Mateus O, Flisch A, Patthey M, Rauhut OW. 2015. New insights into the lifestyle of Allosaurus (Dinosauria: theropoda) based on another specimen with multiple pathologies. PeerJ. 3:e940.

Galton PM. 1977. The ornithopod dinosaur Dryosaurus and a LaurasiaGondwanaland connection in the Upper Jurassic. Nature. 268(5617):230-232.

Galton PM. 1981. Dryosaurus, a hypsilophodontid dinosaur from the Upper Jurassic of North America and Africa. Postcranial skeleton. Paläontol Z. 55 (3-4):271-312.

Galton PM. 1983. The cranial anatomy of Dryosaurus, a hypsilophodontid dinosaur from the Upper Jurassic of North America and East Africa, with a review of hypsilophodontids from the Upper Jurassic of North America. Geol Et Palaeontol. 17:07-243.

Galton PM. 2007. Teeth of ornithischian dinosaurs (mostly Ornithopoda) from the Morrison Formation (Upper Jurassic) of Western United States. In: Carpenter K, editor. Horns and Beaks - ceratopsian and ornithopod dinosaurs. Bloomington: Indiana University Press; p. 17-47.

Galton PM, Jensen JA. 1973. Skeleton of a hypsilophodontid dinosaur (Nanosaurus (?) rex) from the Upper Jurassic of Utah. Brigham Young Univ Geol Stud. 20(4):137-157.

Gilmore CW 1912. The mounted skeletons of Camptosaurus in the United States National Museum. Proceedings of the US National Museum 41(1878):687-696.

Gilmore CW. 1925. Osteology of ornithopodous dinosaurs from Dinosaur National Monument, Utah. Mem Carnegie Mus. 10(4):385-410.

Gross J, Rich T, Vickers-Rich P. 1993. Dinosaur bone infection. Res Explor. 9:286-293.

Haller JM, Githens M, Dunbar R. 2017. Intramedullary nailing for pilon nonunions. J Orthop Trauma. 110:e395-e399. doi:10.1097/BOT.000000000 000912

Han F-L, Barrett PM, Butler RJ, Xu X. 2012. Postcranial anatomy of Jeholosaurus shangyuanensis (Dinosauria, Ornithischia) from the Lower 
Cretaceous Yixian Formation of China. J Vertebr Paleontol. 32(6):1370 -1395 .

Hanna RR. 2002. Multiple injury and infection in a sub-adult theropod dinosaur Allosaurus fragilis with comparisons to allosaur pathology in the ClevelandLloyd Dinosaur Quarry collection. J Vertebr Paleontol. 22(1):76-90.

Hearn L, Williams ACDC. 2019. Pain in dinosaurs: what is the evidence? Philos T R Soc B. 374(1785):20190370.

Hedrick BP, Gao C, Tumarkin-Deratzian AR, Shen C, Holloway JL, Zhang F, Dodson P. 2016. An injured Psittacosaurus (Dinosauria: ceratopsia) from the Yixian formation (Liaoning, China): implications for Psittacosaurus biology. Anat Rec. 299:897e906. doi:10.1002/ar.23363

Helfet DL, Koval K, Pappas J, Sanders RW, Di Pasqule T. 1994. Intraarticular "pilon" fracture of the tibia. Clin Orthop Relat Res. 298:221-228.

Herne MC, Tait AM, Weisbecker V, Hall M, Nair JP, Cleeland M, Salisbury SW. 2018. A new small-bodied ornithopod (Dinosauria, Ornithischia) from a deep, high-energy Early Cretaceous river of the Australian-Antarctic rift system. PeerJ. 5:e4113.

Hill A, Behrensmeyer AK. 1984. Disarticulation patterns of some modern east African mammals. Paleobiology. 10:366-376.

Hunt TC, Peterson JE, Frederickson JA, Cohen JE, Berry JL. 2019. First documented pathologies in Tenontosaurus tilletti with comments on infection in non-avian dinosaurs. Sci Rep. 9(1):8705.

Jacobson JA, Girish G, Jiang Y, Sabb BJ. 2008. Radiographic evaluation of arthritis: degenerative joint disease and variations. Radiology. 248(3):737-747.

Kappelman J, Ketcham RA, Pearce S, Todd L, Akins W, Colbert MW, Feseha M, Maisano JA, Witzel A. 2016. Perimortem fractures in Lucy suggest mortality from fall out of tall tree. Nature. 537(7621):503.

Macdonald I, Currie PJ. 2018. Description of a partial Dromiceiomimus (Dinosauria: theropoda) skeleton with comments on the validity of the genus. Can J Earth Sci. 56(2):129-157.

Marsh OC. 1894. The typical Ornithopoda of the American Jurassic. Am J Sci Serie. 3(48):5-90.

Marsh OC 1896. The dinosaurs of North America. U.S. Geological Survey Annual Report for 1894-1895:133-244.

McCrea RT, Tanke DH, Buckley LG, Lockley MG, Farlow JO, Xing L, Matthews N, Helm CW, Pemberton SG, Breithaupt BH. 2015. Vertebrate ichnopathology: pathologies inferred from dinosaur tracks and trackways from the Mesozoic. Ichnos. 22(3-4):235-260.

Norman DB. 2004. Basal Iguanodontia. In: Weishampel DB, Dodson P, Osmólska H, editors. The Dinosauria. 2nd ed. Berkeley: University of California Press; p. 413-437.

Norman DB, Witmer LM, Weishampel DB. 2004. Basal Ornithischia. In: Weishampel DB, Dodson P, Osmólska H, editors. The Dinosauria. 2nd ed. Berkeley: University of California Press; p. 325-334.

Ostrom JH, McIntosh JS. 1966. Marsh's Dinosaurs. The collections from Como Bluff. New Haven: Yale University Press.

Peterson JE, Vittore CP. 2012. Cranial pathologies in a specimen of Pachycephalosaurus. PLoSONE. 7(4):e36227. doi:10.1371/journal.pone.0 036227

Ramírez-Velasco AA, Morales-Salinas E, Hernández-Rivera R, Tanke DH. 2017. Spinal and rib osteopathy in Huehuecanauhtlus tiquichensis (Ornithopoda: hadrosauroidea) from the Late Cretaceous in Mexico. Hist Biol. 29:208-222.

Resnick D. 2002. Diagnosis of bone and joint disorders. Philadelphia: WB Saunders.
Rose SC, Fujisaki CK, Moore EE. 1988. Incomplete fractures associated with penetrating trauma: etiology, appearance, and natural history. J Trauma Acute Care Surg. 28:106-109.

Rothschild BM. 1990. Radiologic assessment of osteoarthritis in dinosaurs. Ann Carnegie Mus. 59:295-301.

Rothschild BM. 2005. Osseotypes and spondyloarthropathy exposed. Curr Rheumatol Rev. 1(1):57-63.

Rothschild BM. 2007. CPPD complicating other forms of inflammatory arthritis. Clin Rheumatol. 26(7):130-1131.

Rothschild BM. 2009. Scientifically rigorous reptile and amphibian osseous pathology: lessons for forensic herpetology from comparative and paleopathology. App Herpetol. 6(1):47-79.

Rothschild BM. 2010. Macroscopic recognition of nontraumatic osseous pathology in the postcranial skeletons of crocodilians and lizards. J Herpetol. 44 (1):13-20.

Rothschild BM, Schultze HP, Pellegrini R. 2013. Osseous and other hard tissue pathologies in turtles and abnormalities of mineral deposition. In: Brinkman D, Holroyd P, Gardner J, editors. Morphology and evolution of turtles. Dordrecht: Springer; p. 501-534.

Rothschild BM, Bruno MA. 2009. Imaging in calcium pyrophosphate deposition disease. eMedicine Radiology. [updated 2016 Jan 11; accessed 2011 Mar 25]. http://emedicine.medscape.com/article/388348-overview.

Rothschild BM, Martin L. 2006. Skeletal impact of disease. Bull New Mexico Mus Nat Hist Sci. 33:1-5.

Rothschild BM, Tanke DH. 2006. Osteochondrosis in Late Cretaceous Hadrosauria: a manifestation of ontologic failure. In: Carpenter K, editor Horns and Beaks. Ceratopsian and Ornithopod Dinosaurs. Bloomington: Indiana University Press; p. 171-183.

Rothschild BM, Schultze HP, Pellegrini R. 2012. Herpetological Osteopathology: annotated bibliography of amphibians and reptiles. New York: Springer Science

Straight WH, Davis GL, Skinner HCW, Haims A, McClennan BL, Tanke DH. 2009. Bone lesions in hadrosaurs: computed tomographic imaging as a guide for paleohistologic and stable-isotopic analysis. J Vertebr Paleontol. 29(2):315-325.

Sues H-D, Norman DB. 1990. Hypsilophodontidae, Tenontosaurus, Dryosauridae. In: Weishampel DB, Dodson P, Osmólska H, editors. The Dinosauria. 2nd ed. Berkeley: University of California Press; p. 498-509.

Sullivan RM, Tanke DH, Rothschild BM. 2000. An impact fracture in an ornithomimid (Ornithomimosauria: dinosauria) metatarsal from the Upper Cretaceous (Late Campanian) of New Mexico. Bull New Mexico Mus Nat Hist Sci. 17:109-111.

Tanke DH, Rothschild BM. 2014. Paleopathology in Late Cretaceous Hadrosauridae from Alberta, Canada with comments on a putative Tyrannosaurus bite injury on an Edmontosaurus tail. In: Eberth DA, Evans DC, editors. Hadrosaurs. Bloomington and Indianapolis: Indiana University Press; p. 540-572.

Thulborn T. 1990. Dinosaur tracks. London: Chapman and Hall.

Voorhies MR. 1969. Taphonomy and population dynamics of an early Pliocene vertebrate fauna, Knox County, Nebraska. Vol. 1, Special paper 1 . Laramie: University of Wyoming, Contributions to Geology; p. 1-69.

Waldron T. 2008. Palaeopathology. Cambridge: Cambridge University Press.

Witzmann F, Asbach P, Remes K, Hampe O, Hilger A, Paulke A. 2008. Vertebral pathology in an ornithopod dinosaur: a hemivertebra in Dysalotosaurus lettowvorbecki from the Jurassic of Tanzania. Anat Rec. 291(9):1149-1155.

Wolfe SW, Katz LD. 1995. Intra-articular impaction fractures of the phalange. J Hand Surg. 20A:327-333. 